\title{
Osteoid Osteoma of the Metacarpal-A Case Report
}

\author{
Prince Gupta • R. Rammohan • Lalit Maini • \\ Virender Kumar Gautam • Nita Khurana
}

Received: 26 February 2014 / Accepted: 14 July 2014 /Published online: 6 August 2014

(C) Society of the Hand \& Microsurgeons of India 2014

\section{Introduction}

Osteoid osteoma is a primary benign, bone forming tumor of the growing skeleton. It was first described in 1935 by Jaffe [1]. Osteoid osteomas constitute $10 \%$ of benign bone tumors and is usually seen in the first two decades of life [2]. Osteoid osteoma was reported to usually affect long tubular bones [3]. With only 6 to $13 \%$ of osteoid steomas affecting hand and wrist region, it may be missed at initial physical and radiological evaluation $[4,5]$. A review of literature revealed that a few cases of metacarpal osteoid osteoma have been reported. Here we present a rare case of osteoid osteoma of metacarpal bone in a young patient.

\section{Case Report}

A 36 year old right handed female patient presented to our hospital with a history of pain in left middle finger since 1 year with no history of any antecedent trauma. The pain was dull aching and localized, aggravated by activity and relieved by analgesics. Assuming a musculoskeletal pain, the initial treatment given by the patient's general practitioner consisted of analgesics. The patient did not get relief and she presented to us with complaint of persistent pain. The pain was not associated with nocturnal increase and was not relieved by salicylates. On examination, the overlying skin was healthy with no local swelling. There was tenderness over the third

P. Gupta $\cdot$ R. Rammohan $\cdot$ L. Maini $\cdot$ V. K. Gautam $\cdot$ N. Khurana Maulana Azad Medical College and Associated Lok Nayak Hospital, New Delhi 110002, India

P. Gupta $(\bowtie)$

House No 172, Sector 12 a, Gurgaon 122001, Haryana, India

e-mail: dr.princegupta@gmail.com metacarpal distally. Radiographs revealed an expansile, eccentric lesion seen in the distal diaphysis of the third metacarpal (Fig. 1a, b). Gadolinium contrast enhanced MRI of the left hand was done which revealed a well defined eccentric, enhancing lytic lesion with sharp margins in the distal diaphysis of the third metacarpal on the radial aspect which was hypo intense in T1 weighted images and hyper intense T2 weighted/T2 Fat sat images with calcification specks within (Fig. 2).

After complete work up, the patient was posted for curettage and biopsy of the lesion. A longitudinal incision was given over the dorsal aspect of the involved metacarpal and after retracting the tendon and soft tissues, the lesion which was on radiovolar aspect of the distal metaphysis was removed piecemeal and the margins were freshened with the help of high speed burr (Fig. 3). Here it was interesting to see that there was no sclerotic bone around the tumor, which is an unusual finding in osteoid osteoma. Postoperatively the hand was immobilized in a splint until suture removal. Histologically nidus was present within irregular bony trabeculae amidst surrounding vascularised connective tissue which was consistent with the diagnosis of osteoid osteoma (Fig. 4). After 1 month, the patient was relieved of pain and full range of motion of the involved finger could be achieved. Follow up radiographs at 3 and 6 months shows that the lesion is resolving (Fig. 5a, b).

\section{Discussion}

Osteoid osteoma is a relatively uncommon benign osteoblastic tumor, constituting approximately $10 \%$ of all benign bone tumors [2]. It usually affects children and young adults and rarely seen in patients above 40 years of age $[2,6,7]$. Osteoid osteoma has a predilection for lower extremity, with more than half of the lesions occurring near the end of the shaft in tibia 


\section{a}
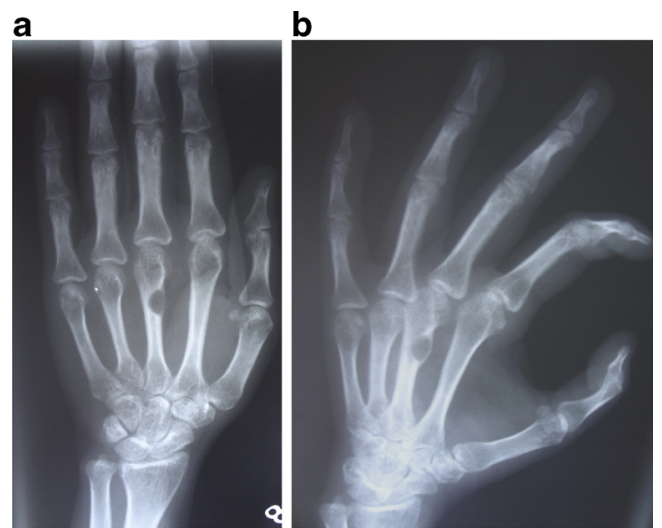

Fig. 1 a Anteroposterior radiograph of hand showing lesion in distal shaft of third metacarpal. b Oblique view of the hand showing lesion in the shaft of third metacarpal

and femur. Approximately $30 \%$ of the lesions are equally distributed among the spine, foot and hand [8]. Osteoid osteoma of the hand has an incidence of about $8 \%$ of all reported cases [9]. However, phalanges are the most frequent sites for osteoid osteoma in hand, followed by the carpal bones and the least commonly seen in metacarpals [10-15]. When the lesion appears in the hand, diagnosis is challenging for three reasons: first, the typical pain pattern may be absent; secondly, lesions in the hand may have unusual clinical signs and radiologic

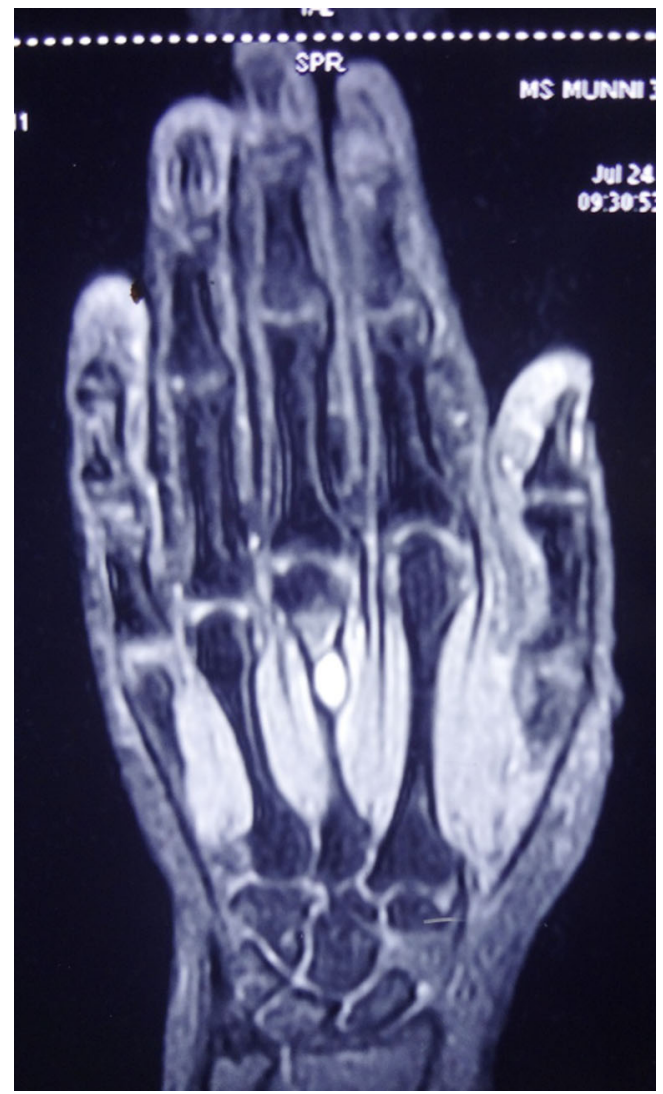

Fig. 2 MRI image showing eccentric lesion in distal shaft of third metacarpal showing hyperintense signal on $\mathrm{T} 2$ image

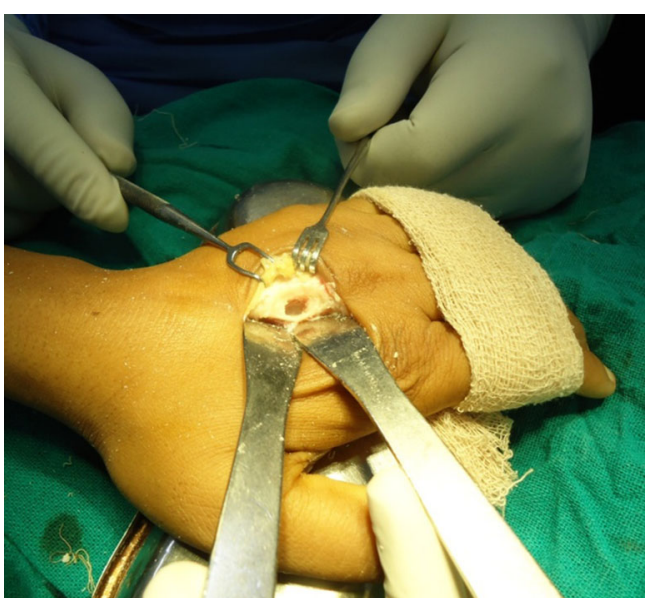

Fig. 3 Intraoperative photograph of the bone after curettage of the lesion

findings; and third, histologic features may differ from classic osteoid osteomas, which occur in the long bones [16]. Clinically, patient presents with complaint of pain and swelling. Some authors have also reported cases in which an injury precedes the onset of lesion. Kendrick and Evarts [17] reported that 15 of their 36 cases had an episode of initial trauma, Bednar et al. [18] 11 of 46 cases, Uda et al. [12] with 13 cases with one case of osteoid osteoma of metacarpal. Pain is usually nocturnal in nature, which is relieved by salicylates. Response rate of salicylates against this pain has been reported to be $73 \%$ [17] however, painless Osteoid osteomas have also been reported in metacarpal by Basu et al. [13] and phalanges by Rex et al. [19].

The diagnosis of an osteoid osteoma in the metacarpal is usually based on clinical and radiographic findings. Osteoid osteomas do not exceed $1 \mathrm{~cm}$ in diameter [20] and the radiographic appearance is characteristic with an oval or round sclerotic nidus surrounded by radiolucent zone. In the metacarpals and phalanges, difficulty in diagnosis may occur as some lesions may display no lytic nidus on any imaging modality and there may be absence of reactive bone sclerosis $[16,21,22]$. In the metacarpals and phalanges, differential

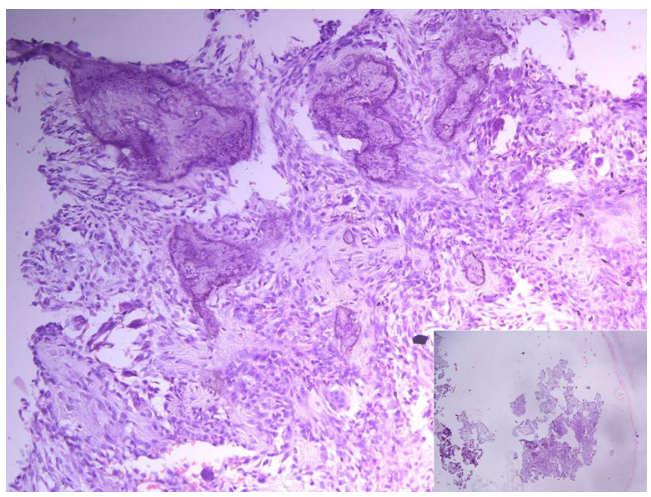

Fig. 4 Histological section showing irregular trabeculae composed of osteoid and woven bone in a stroma of vascular connective tissue (haematoxylin and eosin, magnification $250 \times$ ) 


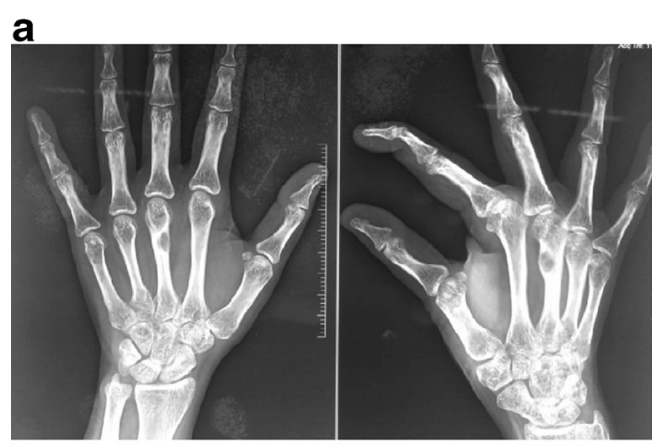

b

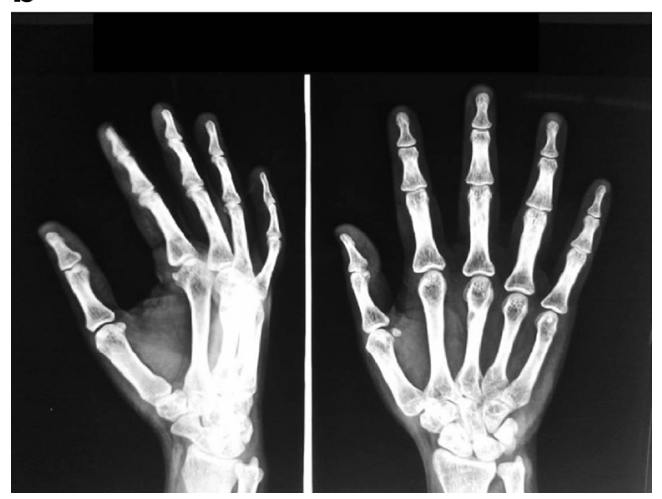

Fig. 5 a, b Follow up radiographs at 3 and 6 months showing resolving lesion

diagnosis radiologically may include syphilitic dactylitis, tuberculosis, other infection, brodies abscess, enchondroma, post traumatic change, osteochondroma, soft tissue tumor $[10,16]$. In the present case report, many of the above differential diagnosis were considered initially, but due to complex anatomy of the upper extremity which did not display the lesion in conventional radiographs classically, definite diagnosis was difficult to make.

Treatment consists of surgical excision of the nidus which is the treatment of choice [23]. However, minimally invasive techniques like radiofrequency ablation [24], thermal destruction with laser photocoagulation [25] and percutaneous trephine or drill resection with or without ethanol injection [26-29] have also been used for nidus removal for treatment of Osteoid osteomas. Recurrence of the osteoid osteoma has also been reported in many cases due to incomplete removal of the nidus [30, 31]. Most recurrences occur in the first 7 months after primary treatment [32]. Patients may experience a symptom free interval after unsuccessful surgery. Most of the recurrences have been recorded after curettage or drilling and rarely after en bloc resection [9].

The present case represents an unusual location of Osteoid osteoma in third metacarpal shaft. Although a rare site for osteoid osteoma, it would be prudent to consider it amongst differential diagnosis of hand tumors. Also, it should be kept in mind that sclerosis cannot always be considered as a key feature of osteoid osteoma of bones of hand. Bone biopsy after curettage or excision is the diagnostic and therapeutic solution.

Conflicts of Interest No benefits in any form have been received or will be received from a commercial party related directly or indirectly to the subject of this article. Necessary institutional clearance and patients consent have been obtained. All precautions and steps have been taken in protecting the identity of this patient.

\section{References}

1. Jaffe HL (1935) Osteoid osteoma: a benign osteoblastic tumor composed of osteoid and atypical bone. Arch Surg 31:709-728

2. Resnick D, Niwayama G (1988) Tumors and tumor like diseases. In: Diagnosis of bone joint disorders. Saunders, Philadelphia, pp 36213635

3. Kayser F, Resnick D, Haghighi P, Pereira Edo R, Greenway G, Schweitzer M et al (1998) Evidence of the subperiosteal origin of osteoid osteomas in tubular bones: analysis by CT and MR imaging. AJR Am J Roentgenol 170:609-614

4. Bulbul M, Ayanoglu S, Ozturk K, Gurkan V, Gurbuz H, Bilgiç B (2010) Osteoid osteoma of a mecacarpal bone: case report. Trakya Univ Tip Fak Derg 27(2):209-211

5. Marcuzzi A, Leti Acciaro A, Landi A (2002) Osteoid osteoma of the hand and wrist. J Hand Surg (Br Eur) 27 B(5):440-443

6. Cohen JD, Harrington TM, Ginsberg WW (1983) Osteoid osteoma: 95 cases and a review of the literature. Semin Arthritis Rheum 12: 265-281

7. Healey JH, Ghelman B (1986) Osteoid osteoma and osteoblastoma: current concepts and recent advances. Clin Orthop 204:76-85

8. Kransdorf MJ, Stull MA, Gilkey FW, Moser RP Jr (1991) Osteoid osteoma. Radiographics 11:671-696

9. Chronopoulos E, Xypnitos FN, Nikolaou VS, Efstathopoulos N, Korres D (2008) Osteoid osteoma of a metacarpal bone: a case report and review of the literature. J Med Case Rep 2:285

10. Carroll RE (1953) Osteoid osteoma in the hand. J Bone Joint Surg Am 35 A:888-893

11. Muren C, Hoglund M, Engkvist O, Juhlin L (1991) Osteoid osteoma of the hand. Report of three cases and review of the literature. Acta Radiol 32:62-66

12. Uda H, Mizuzeki T, Tsuge K (2002) Osteoid osteoma of the metacarpal bone presenting after an injury. Scand J Plast Reconstr Surg Hand Surg 36:238-242

13. Basu S, Basu P, Dowell JK (1999) Painless osteoid osteoma in a metacarpal. J Hand Surg (Br) 24:133-134

14. Kallio E (1963) Osteoid osteoma of the metacarpal and metatarsal bones. Acta Orthop Scand 33:246-252

15. Wachtl SW, Exner GU, von Hochstetter A, Sennwald G (1995) Osteoid osteoma of the hand. Case presentation with special reference to magnetic resonance tomography and literature review. $\mathrm{Z}$ Orthop lhre Grenzgeb 133:76-78

16. Burger IM, McCarthy EF (2004) Phalangeal osteoid osteomas in the hand: a diagnostic problem. Clin Orthop Relat Res 427:198-203

17. Kendrick JI, Evarts CM (1967) Osteoid osteoma: a critical analysis of 40 tumors. Clin Orthop 54:51-59

18. Bednar MS, McCormack RR Jr, Glasser D, Weiland AJ (1993) Osteoid osteoma of the upper extremity. J Hand Surg 18A:10191025

19. Rex C, Jacobs L, Nur Z (1997) Painless osteoid osteoma of the middle phalanx. J Hand Surg 22 B:798-800 
20. Dick HM (1982) Bone tumours. In: Green DP (ed) Operative hand surgery. Churchill Livingstone, New York, p 1684

21. Meng QF, Watt I (1989) Phalangeal osteoid osteoma. Br J Radiol 62(736):321-325

22. Themistocleous GS, Chloros GD, Benetos IS, Efstathopoulos DG, Gerostathopoulos NE, Soucacos PN (2006) Osteoid osteoma of the upper extremity. A diagnostic challenge. Chirurgie Main 25:69-76

23. Desmet L, Fabry G (1995) Osteoid osteoma of the hand and carpus: peculiar presentations and imaging. Acta Orthop Belg 61:113-116

24. de Berg JC, Pattynama PM, Obermann WR, Bode PJ, Vielvoye GJ, Taminiau AH (1995) Percutaneous computed tomography guided thermocoagulation for osteoid osteomas. Lancet 346:350-351

25. Gangi A, Dietemann JL, Guth S, Vinclair L, Sibilia J, Mortazavi R, Steib JP, Roy C (1998) Percutaneous laser photocoagulation of spinal osteoid osteomas under CT guidance. AJNR AMJ Neuroradiol 19: 1955-1958

26. Towbin R, Kaye R, Meza MP, Pollock AN, Yaw K, Moreland M (1995) Osteoid osteoma: percutaneous excision using a CT guided coaxial technique. AJR AMJ Roentgenol 164:945-949
27. Ward WG, Eckardt JJ, Shayestenfar S, Mirra J, Grogan T, Oppenham W (1993) Osteoid osteoma diagnosis and management with low morbidity. Clin Orthop Relat Res 291:229-235

28. Adam G, Neverburg J, Vorwerk D, Forst J, Gunther RW (1997) Percutaneous treatment of osteoid osteomas: combination of drill biopsy and subsequent ethanol injection. Semin Musculoskelet Radiol 1:281-284

29. Dude SH, Schnatterbeck P, Harer T, Giehl J, Bohm P, Claussen CD (1997) Treatment of osteoid osteoma with CT guided drilling and ethanol instillation. Dtsch Med Wochenschr 122:507-510

30. Norman A (1978) Persistence or recurrence of pain: a sign of surgical failure is osteoid osteoma. Clin Orthop Relat Res 130:263-266

31. Voto SJ, Cook AJ, Weiner DS, Ewing JW, Arrington LE (1990) Treatment of osteoid osteoma by computed tomography guided excision in the paediatric patient. J Paediatr Orthop 10: $510-513$

32. Vanderschueren GM, Taminiau AH, Obermann WR (2002) Bloem JL: osteoid osteoma : clinical results with thermocoagulation. Radiology 224:82-86 